\title{
El comercio exterior de China y su relación con México. Una perspectiva histórica
}

\section{Introducción}

$\mathrm{E}$ 1 intercambio de productos y servicios es una actividad inherente al ser humano. En China, desde la más remota antigüedad, encontramos registros de sus relaciones comerciales internas y externas. Incluso, durante algunas épocas en que el régimen imperial desestimuló la actividad comercial por considerarla improductiva, ésta persistió ante la necesidad del propio desarrollo económico.

En la antigüedad China y México desarrollaron su propio comercio exterior en el contexto del desarrollo regional, limitado principalmente por el desarrollo tecnológico de la época y de la perspectiva geopolítica de sus dirigentes. El descubrimiento y la conquista de América y la posterior colonización de Asia, África y Oceanía por parte de las potencias europeas, configuró el esquema sobre el cual se desarrollaría el comercio transcontinental, incluyendo la intensa relación directa entre China y México (Nueva España). Desde entonces la relación comercial de China y México se ubica en el contexto del surgimiento y evolución de la economía mundial y del proceso de globalización.

* Profesor-Investigador del Departamento de Estudios del Pacífico de la Universidad de
Sin embargo, durante una buena parte de los siglos XIX y xx el comercio directo entre China y México prácticamente fue inexistente. La lucha por la independencia de México y el desorden interno de China los mantuvo ajenos a una relación comercial directa. La reanudación de las relaciones comerciales directas entre China y México volvió a tener lugar en los años setenta del siglo pasado, con las exportaciones e importaciones de algunos productos básicos en volúmenes reducidos y de manera esporádica. El proceso actual de crecimiento impresionante se inicia en los años ochenta del siglo pasado y se da de nuevo en el contexto del intercambio global, con relaciones directas y triangulares que responden, fundamentalmente, a la lógica de la nueva división internacional de trabajo.

En suma, a lo largo de la historia los volúmenes de comercio entre ambos países han presentado drásticos altibajos por razones fundamentalmente políticas, tanto internas de ambos países como del sistema político internacional.

\section{El comercio exterior de China}

Los primeros registros sobre el comercio exterior de China se remontan a los contactos de la Dinastía Han (206 a. de C. a 220 d. de C.) con el Imperio Romano Guadalajara y miembro del SNI. ORCID http://orcid.org/0000-0002-9145-5865 
a través de la Ruta de Seda. Producto de esta relación comercial, ambos imperios realizaron esfuerzos por tener contactos directos: el primer esfuerzo - infructuoso, por cierto- por llegar a Roma lo realizó Zhang Qian en el año 97. Sin embargo, en el año 166, después de que Roma venció a los partos, el enviado romano de Marco Aurelio arribó a China. Desde entonces y hasta la "irrupción de Occidente" a finales del siglo xviI la política comercial de China fue un reflejo de la imagen que del mundo y de sí mismo tenía el imperio. El comercio con el exterior, sobre todo con las naciones vecinas, se realizaba mediante el "comercio tributario". ${ }^{1}$

En el intervalo de los dos últimos milenios tuvieron lugar dos aspectos de trascendencia histórica relacionados con el comercio de China: el primero se refiere al estímulo otorgado por la Dinastía Song (960-1279) al comercio marítimo, sobre todo con las naciones del sudeste de Asia, el cual habría de mantenerse sin intentos de conquista o colonización hasta el siglo XVII cuando las potencias marítimas europeas irrumpieron en Asia con una estrategia de comercio colonial. El segundo se refiere al viaje de Marco Polo a lo largo de uno de los caminos de la Ruta de de la Seda hasta alcanzar Beijing en 1266 durante la dinastía Yuan, y su regreso como enviado del Kublai Khan con una carta para el Papa, junto con su tío Mateo (Borthwick, 1992: 36 y 71).

Los esfuerzos por abrir el mercado de China, por parte de las potencias de la época, encabezadas por Gran Bretaña, se iniciaron a finales del siglo xviII y se concretizaron a principio de siglo XIX con los tratados desiguales firmados por la Dinastía Qing. Con la derrota en las guerras del opio los ejércitos invasores comenzaron a ocupar las regiones estratégicas del impe- rio, y China no pudo más que ceder frente a las exigencias de apertura comercial y cesión de soberanía que se le imponía por medio de los tratados (Borthwick, 1992: 90-91).

Los primeros contactos comerciales entre China y México (Nueva España) se iniciaron en 1571 con la fundación de Manila y el nacimiento del comercio transpacífico y mundial. Como Fynn y Giráldez afirman: "[...] el comercio sustancial y continuo entre Asia y América no existe antes de la fundación de la ciudad de Manila". De hecho, el rentable comercio traspacífico financió las ambiciones geo-militares del imperio español en aguas asiáticas. El repentino surgimiento del substancial comercio entre Acapulco, Manila y China continental dependió básicamente de dos industrias: la plata, producida en la América española y con destino final el mercado de China; y la seda, producida en China y destinada a la América Española. ${ }^{2}$

Durante las últimas dinastías, los barcos chinos comerciaron a través de los mares de Asia y alcanzaron las costas africanas, mientras que las caravanas extendieron sus contactos comerciales hasta Asia Central y el Medio Oriente. No obstante estos contactos comerciales, el imperio chino nunca consideró al comercio exterior como una actividad económica importante. Los eruditos confucianos veían a los comerciantes como parásitos y los ubicaron en la parte más baja de la jerarquía social; además, los emperadores creían que su país era por completo autosuficiente.

A finales del siglo XVIII los países europeos trataron de abrir el mercado chino a sus productos. Frente a los intentos infructuosos, utilizaron la fuerza militar para establecer un comercio sustancial con China. Estos sucesos coinciden con el desarrollo del imperialismo, en el sentido 
del uso militar de la fuerza para respaldar la hegemonía económica y el engrandecimiento territorial (Borthwick, 1992: 9091). Consecuentemente, desde el tiempo de la Guerra del Opio (1839-1842), varias potencias occidentales - y Japón a partir del decenio de 1890 - obligaron a China a firmar una serie de tratados desiguales que daban a los extranjeros la posibilidad de establecer bases económicas y operar con estatus de privilegio en China.

Para este momento histórico el comercio global se había expandido de manera significativa. Entre 1800 y 1840 el comercio mundial se había duplicado. Dicho comercio se incrementó 260\% entre 1850 y 1870 . $\mathrm{Al}$ acelerarse los intercambios comerciales mundiales la importancia de China aumentó, en especial a través de la estructura comercial de la Gran Bretaña. Asimismo, a principios del siglo xx la participación de Japón en el comercio exterior de China se incrementó de manera significativa, ya que entre 1909-1911 alcanzó 15\% como destino de sus exportaciones y $15.9 \%$ como origen de sus importaciones (tabla 1). La evolución de la distribución geográfica del comercio durante los siglos XIX y XX muestra una muy clara dependencia económica de los factores políticos (tablas 1 y 2).

El establecimiento de la República Popular China vino a poner fin a un siglo de intervenciones extranjeras, levantamientos sociales, guerras civiles y desórdenes económicos y administrativos, con elevadísimos costos sociales. A lo largo de los primeros treinta años de la República Popular, el comercio exterior no tuvo ninguna relevancia dentro de la economía china. Durante los años cincuenta y sesenta, el valor total del comercio exterior fue de solamente $2 \%$ del producto nacional bruto (PNB), aproximadamente. Según estadísticas oficiales de China, en los años setenta creció rápidamente, pero aun así en 1979 el comercio apenas alcanzó 6\% del PNB. Sin embargo, en los últimos años la relación entre el comercio exterior y el producto

Tabla 1

China: la distribución geográfica del comercio de mercancías, 1871-1911 (porcentajes)

\begin{tabular}{|c|c|c|c|c|c|c|c|c|}
\hline Periodo & $\begin{array}{l}\text { Gran } \\
\text { Bretaña }\end{array}$ & $\begin{array}{l}\text { Hong } \\
\text { Kong }\end{array}$ & Japón ${ }^{a}$ & EEUU & $\begin{array}{l}\text { URSS/ } \\
\text { Rusia }\end{array}$ & Alemania $^{b}$ & Francia $^{b}$ & Otros \\
\hline \multicolumn{9}{|c|}{ Destino de la exportaciones } \\
\hline $1871-1873$ & 34.7 & 32.5 & 3.7 & 0.5 & 0.2 & $0.0^{*}$ & $0.0^{*}$ & 13.3 \\
\hline $1881-1883$ & 23.8 & 36.2 & 4.9 & 3.7 & 0.2 & $0.0^{*}$ & $0.0^{*}$ & 19.2 \\
\hline $1891-1893$ & 20.4 & 51.2 & 4.7 & 4.5 & 0.6 & $0.0^{*}$ & $0.0^{*}$ & 23.8 \\
\hline $1901-1903$ & 15.9 & 41.6 & 12.5 & 8.5 & 0.8 & $0.0^{*}$ & $0.0^{*}$ & 26.2 \\
\hline $1909-1911$ & 16.5 & 33.9 & 15.5 & 7.1 & 3.5 & 4.2 & 0.6 & 15.5 \\
\hline \multicolumn{9}{|c|}{ Origen de las importaciones } \\
\hline $1871-1873$ & 52.9 & 14.7 & 1.7 & 14.1 & 3.3 & $0.0^{*}$ & $0.0^{*}$ & 28.4 \\
\hline $1881-1883$ & 33.3 & 25.4 & 2.4 & 12.4 & 7.3 & $0.0^{*}$ & $0.0^{*}$ & 31.2 \\
\hline $1891-1893$ & 11.3 & 39.3 & 7.2 & 9.8 & 8.6 & $0.0^{*}$ & $0.0^{*}$ & 18.6 \\
\hline $1901-1903$ & 4.8 & 40.8 & 12.5 & 10.2 & 5.5 & $0.0^{*}$ & $0.0^{*}$ & 20.7 \\
\hline 1909-1911 & 5.1 & 28.2 & 15.9 & 9 & 12.5 & 3.1 & 10.7 & 18.7 \\
\hline
\end{tabular}

a. Incluye Taiwán.

b. Las cifras de los años de 1871 a 1903 están incluidas en el rubro de otros.

Fuente: Feverweker (s/a). 


\section{Análisis}

Tabla 2

La distribución geográfica del comercio de mercancías, 1952-1996 (porcentajes)

\begin{tabular}{|c|c|c|c|c|c|c|c|}
\hline & $\begin{array}{l}\text { URSS/ } \\
\text { Rusia }\end{array}$ & $\begin{array}{c}\text { Otros países } \\
\text { socialistas }\end{array}$ & EU & Hong Kong & Japón & $\begin{array}{c}\text { Australia y } \\
\text { Canadá }\end{array}$ & $\begin{array}{c}\text { Europa } \\
\text { Occidental }\end{array}$ \\
\hline \multicolumn{8}{|c|}{ Destino de las exportaciones } \\
\hline 1952 & 47.4 & 21.7 & 0.0 & nd & nd & nd & nd \\
\hline 1959 & 49.3 & 23.1 & 0.0 & nd & 0.9 & nd & nd \\
\hline 1965 & 11.1 & 20.9 & 0.0 & 17.4 & 10.9 & 2.7 & 14.7 \\
\hline 1970 & 1.1 & 21.9 & 0.0 & 22.3 & 10.7 & 3.0 & 16.9 \\
\hline 1978 & 2.5 & 12.9 & 3.2 & 22.3 & 19.3 & 2.2 & 12.5 \\
\hline 1996 & 1.1 & 1 & 17.7 & 21.8 & 20.4 & 2.2 & 13.7 \\
\hline \multicolumn{8}{|c|}{ Origen de las importaciones } \\
\hline 1952 & 54.2 & 15.8 & 0.0 & nd & nd & nd & nd \\
\hline 1959 & 46.4 & 19.9 & 0.0 & nd & 0.02 & nd & nd \\
\hline 1965 & 10.3 & 17.6 & 0.0 & 0.3 & 13.9 & 16.8 & 18.9 \\
\hline 1970 & 1.1 & 15.8 & 0.0 & 0.5 & 26.7 & 12.9 & 29.4 \\
\hline 1978 & 2.3 & 12.5 & 8.4 & 0.6 & 29.8 & 9.0 & 22.7 \\
\hline 1996 & 3.7 & 1 & 11.6 & 5.6 & 21 & 4.3 & 15.2 \\
\hline
\end{tabular}

Fuente: Maddison (1999: 89).

\section{Gráfica 1}

La relación entre el PIB y el comercio en algunos países

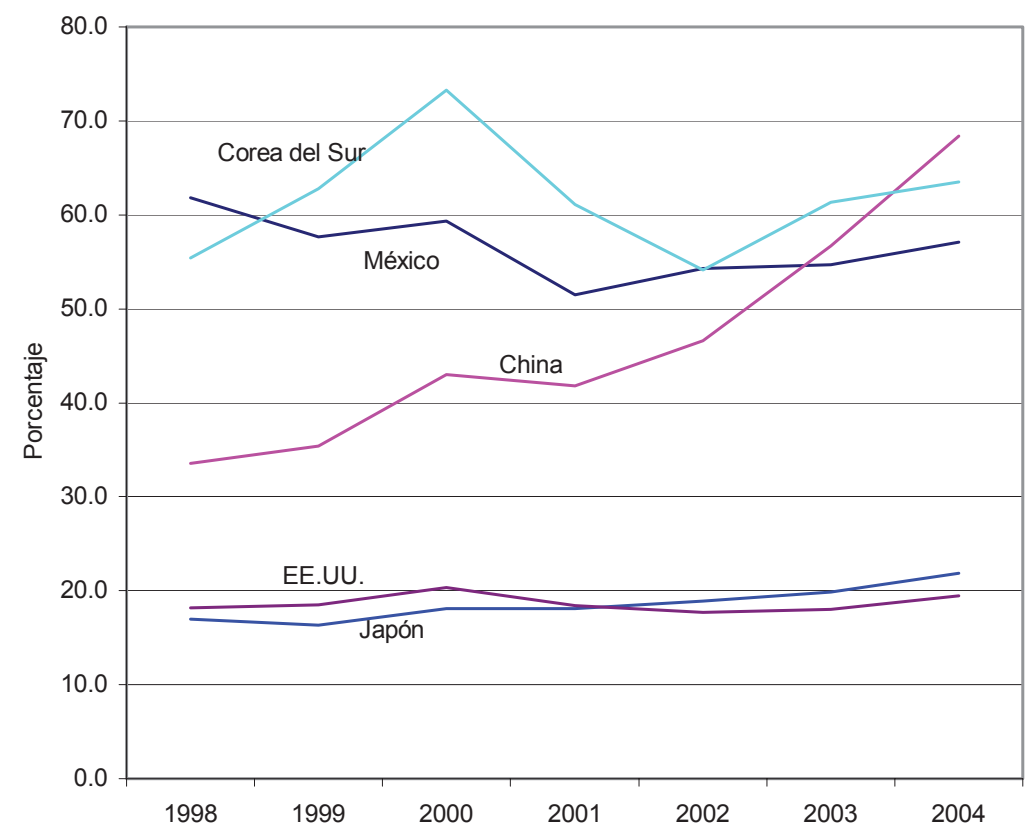

Fuente: IMF (2005). 
interno bruto (РIB) cambió drásticamente. En 1998 el comercio alcanzó 33.6\% del PIB y para 2004 esta relación llegó a 66.4\%, con lo cual China se convirtió en uno de los países más abiertos del mundo (gráfica 1).

La tabla 3 muestra las cifras de comercio exterior de China del último cuarto de siglo. En este periodo el comercio de China pasó de 38,100 millones de dólares (MDD) en 1980 a 1'422,100 MDD en 2005. En este último año, contrariamente a las expectativas y las declaraciones oficiales de búsqueda de un comercio más equilibrado, China obtuvo un superávit sin precedentes en su balanza comercial de más de 100,000 MDD. Sólo en los últimos 20 años (de 1985 a 2005) sus relaciones comerciales con el exterior crecieron en un promedio anual de $16.8 \%{ }^{3}$

La rápida expansión del comercio de China no carece de antecedentes, tanto en tasas de crecimiento como en su amplitud temporal. Otras economías de Asia como Japón, Corea del Sur y las naciones de reciente industrialización fueron capaces de mantener altas tasas de crecimiento en sus exportaciones durante aproximadamente 30 años. Ello implica que China puede mantener altas tasas de crecimiento de sus exportaciones durante algunos años más. Sin embargo, dado el tamaño de la economía de China, su disponibilidad de recursos, el tamaño de su población y su substancial potencial de desarrollo — como se refleja en su actual ingreso per cápita de sólo 1,060 dólares—, el impacto sobre la economía global podría ser mucho mayor (Rumbaugh y Blancher, 2004: 1).

El incremento del comercio exterior de China ha tenido lugar no solamente por la política de apertura hacia el exterior, sino por la transformación de su estructura productiva. Como se aprecia en la tabla 4, los bienes primarios que en 1990
Tabla 3

El comercio exterior de China, 1980-2005 (en miles de millones de dólares)

\begin{tabular}{lrrrr}
\hline Año & \multicolumn{1}{c}{ Total } & Export. & Import. & Saldo \\
\hline 1980 & 38.1 & 18.1 & 20.0 & -1.9 \\
1985 & 69.6 & 27.4 & 42.3 & -14.9 \\
1986 & 73.9 & 30.9 & 42.9 & -12.0 \\
1987 & 82.7 & 39.4 & 43.2 & -3.8 \\
1988 & 102.8 & 47.5 & 55.3 & -7.8 \\
1989 & 116.8 & 52.5 & 59.1 & -6.6 \\
1990 & 115.4 & 62.1 & 53.4 & 8.7 \\
1991 & 135.7 & 71.9 & 63.8 & 8.1 \\
1992 & 165.5 & 84.9 & 80.6 & 4.3 \\
1993 & 195.7 & 91.7 & 104.0 & -12.2 \\
1994 & 236.6 & 121.0 & 115.6 & 5.4 \\
1995 & 280.9 & 148.8 & 132.1 & 16.7 \\
1996 & 289.9 & 151.1 & 138.8 & 12.2 \\
1997 & 325.2 & 182.7 & 142.4 & 40.3 \\
1998 & 324.0 & 183.8 & 140.2 & 43.6 \\
1999 & 353.0 & 194.9 & 165.7 & 29.2 \\
2000 & 463.8 & 249.2 & 225.1 & 24.1 \\
2001 & 498.2 & 266.2 & 243.6 & 22.6 \\
2002 & 607.2 & 325.6 & 295.2 & 30.4 \\
2003 & 794.8 & 438.4 & 412.8 & 25.6 \\
2004 & $1,156.8$ & 595.4 & 561.4 & 34.0 \\
2005 & $1,422.1$ & 762.0 & 660.1 & 101.9 \\
\hline & & & &
\end{tabular}

a. Las exportaciones son reportadas con cifras FOB y las importaciones con cifras CIF.

Fuente: Ministerio de Comercio Exterior y Cooperación Económica y PRC General. Administration of Customs, China's Customs Statistics.

representaron $25.9 \%$ de las exportaciones chinas disminuyeron a $9.2 \%$ en 2005 . Por otra parte, en 1990 las manufacturas participaron con $74.1 \%$ de las exportaciones y en 2005 pasaron a $90.5 \%$. La disminución de las manufacturas intensivas en mano de obra y el incremento en las manufacturas de tecnología media y alta, en la estructura de las exportaciones totales, explican la preponderancia de los productos industrializados en los mercados internacionales. 
Tabla 4

China: la estructura de sus exportaciones totales (en porcentajes)

\begin{tabular}{lrrrr}
\hline & 1990 & 1995 & 2000 & $2005 a$ \\
\hline Total & 100.0 & 100.0 & 100.0 & 100.0 \\
Bienes primarios & 25.9 & 14.9 & 10.9 & 9.2 \\
Manufacturas & 74.1 & 85.1 & 89.1 & 90.8 \\
$\begin{array}{l}\text { Intensivas en mano } \\
\text { de obra }\end{array}$ & 57.8 & 50.9 & 41.9 & 39.8 \\
Baja tecnología & 11.5 & 11.0 & 9.2 & 9.0 \\
Tecnología media & 10.5 & 13.2 & 17.5 & 16.4 \\
Alta tecnología & 20.2 & 24.8 & 31.4 & 34.8 \\
\hline
\end{tabular}

a. Datos preliminares.

Fuente: Centro de Estudios de las Finanzas Públicas de la H. Cámara de Diputados y UNCTAD.

Por otra parte, la orientación del comercio ha cambiado de manera significativa. China se ha convertido en un socio cada vez más importante para el resto de los países asiáticos. Ahora funciona como plataforma final del proceso de ensamble para una gran cantidad de productos importados de la región, que una vez convertidos en bienes de consumo son exportados al resto del mundo. De este modo, el déficit en la balanza comercial de China con los países asiáticos es compensado con creces por el progresivo superávit logrado con los países desarrollados y en vías de desarrollo, entre los que se cuenta México.

La integración de China a la economía global ha contribuido al crecimiento sostenido del comercio internacional. Tanto las exportaciones como las importaciones de China han crecido más rápidamente que el comercio mundial duramente más de 20 años. Como reflejo de esta creciente necesidad de bienes importados -incluyendo los necesarios para hacer frente a su demanda interna-, China ha contribuido de manera importante a mantener el crecimiento de la economía mundial, sobre todo porque en los últimos años otras economías mostraron estancamientos o crecimientos muy bajos. Entre 2001 y 2003 China logró aproximadamente $24 \%$ del crecimiento mundial, si consideramos su PIB en términos de la paridad del poder de compra. La importaciones de China de todos sus socios comerciales están creciendo rápidamente, al grado de que ahora es el tercer mayor importador de los países en desarrollo, después de Estados Unidos y la Unión Europea. China también ha contribuido al reforzamiento de los precios de las mercancías a escala mundial; actualmente, es el principal importador de cobre y acero, y está entre los principales importadores de otras materias primas como el mineral de hierro y el aluminio (Rumbaugh y Blancher, 2004: 1).

No obstante que la integración de China al comercio mundial puede beneficiar tanto a las economías globales como a las regionales, no hay duda de que algunas regiones y países aprovechen de mejor manera la apertura del mercado chino. Los países que más se benefician de la expansión del comercio chino incluyen a los exportadores de capital, tecnología, materias primas y recursos naturales; mientras que los países que se han especializado en exportaciones intensivas en mano de obra, similares a las de China, tendrán que realizar ajustes significativos para poder competir con China en el mercado internacional (Rumbaugh y Blancher, 2004: 2).

\section{La inversión extranjera directa (IED)}

La expansión del comercio exterior de China ha sido un aspecto sobresaliente de su participación en la economía mundial. Este proceso ha sido facilitado por las reformas y la apertura general de la economía que han propiciado el surgimiento de la inversión extranjera directa y la creciente 
integración al sistema de comercio mundial (Prasad, 2004: 1).

La inversión extranjera directa en China creció rápidamente, lo cual va de la mano de la política de apertura iniciada en el decenio de los ochenta. De este modo, de 109 MDD de IED captada en 1979 se pasó a 1,258 MDD en 1984 y a 11,007 MDD en 1992. Como se muestra en la tabla 5, entre 1985 y 1995 el promedio fue de 11, 700 MDD y en los últimos años superó los 60,000 MDD anuales. Sólo en 2004 la inversión extranjera directa en China representó 3.33 veces la IED captada por México, 26\% de la IED captada por los países en desarrollo y $9.3 \%$ de la IED mundial (tabla 5).

La inversión extranjera directa nos permite, asimismo, medir el grado de apertura de la economía china. Según este parámetro, en la actualidad la economía china es una de las más abiertas del mundo. Si miramos la relación entre el comercio y la inversión extrajera directa con el PIB, tenemos los siguientes resultados: en 2002 el comercio exterior de China alcanzó $60.3 \%$ de su PIB, uno de los más altos del mundo. La inversión extranjera directa, por su parte, representó 36.2\% de su PIB. Ello muestra la decisión de la diri- gencia china de participar activamente en la economía mundial.

Tabla 6

La relación del PIB con el comercio exterior y la IED en algunos países, 2002

\begin{tabular}{lrrcr}
\hline & $\begin{array}{r}\text { Población } \\
\text { (millones) }\end{array}$ & $\begin{array}{c}\text { Superficie } \\
\text { (mill. de } \\
\mathrm{km}^{2} \text { ) }\end{array}$ & $\begin{array}{c}\text { Porcentaje } \\
\text { del } \\
\text { comercio }\end{array}$ & $\begin{array}{c}\text { Porcentaje } \\
\text { de la IED }\end{array}$ \\
\hline China & $1,294.9$ & 9.600 & 60.3 & 36.2 \\
India & $1,049.6$ & 3.287 & 22.9 & 5.1 \\
EEUU & 291.4 & 9.628 & 18.8 & 12.9 \\
Brasil & 176.3 & 8.510 & 26.8 & 52.1 \\
Rusia & 144.1 & 17.070 & 52.1 & 6.5 \\
Japón & 127.5 & 0.370 & 18.9 & 1.5 \\
México & 110.0 & 1.973 & 50.9 & 24.0 \\
\hline
\end{tabular}

Fuente: FMI (2005) y UNCTAD.

\section{El comercio entre China y México}

El intercambio comercial entre México y China surge tras la conquista de México y las Filipinas por parte de España en siglo XVI, sucesos que habrían de permitirle al imperio español extender sus dominios en todo el mundo. ${ }^{4}$

España estableció una ruta marítima que iba de China al puerto de Manila en las Filipinas, y de ahí al puerto de Acapul-

Tabla 5

El flujo de inversión extranjera directa en algunos países, 1985-2005

(en miles de millones de dólares)

\begin{tabular}{lrrrrrrrrrr}
\hline & $1985-95$ & 1997 & 1998 & \multicolumn{1}{c}{1999} & \multicolumn{1}{c}{2000} & \multicolumn{1}{c}{2001} & 2002 & 2003 & 2004 & 2005 \\
\hline China & 11.7 & 44.2 & 43.8 & 40.3 & 40.8 & 46.8 & 52.7 & 53.5 & 60.6 & 60.3 \\
México & nd & 14.2 & 12.2 & 13.5 & 17.2 & 27.5 & 17.3 & 12.9 & 18.2 & 17.8 \\
EEUu & 44.4 & 103.4 & 174.4 & 283.4 & 314.0 & 159.5 & 71.3 & 56.8 & 95.9 & nd \\
En el exterior & 42.6 & 95.8 & 131.0 & 209.4 & 142.6 & 124.9 & 134.9 & 119.1 & 229.3 & nd \\
$\begin{array}{l}\text { Países en } \\
\text { desarrollo }\end{array}$ & 50.9 & 191.0 & 187.6 & 225.1 & 237.9 & 204.8 & 155.5 & 166.3 & 233.2 & \\
Mundo & 181.1 & 478.1 & 694.5 & $1,008.3$ & $1,491.9$ & 735.1 & 716.1 & 632.6 & 648.2 & \\
\hline
\end{tabular}

Fuente: China Statistical Yearbook, varios números; Secretaría de Economía de México; UNCTAD; y us Department of Commerce. 
co en la costa de Nueva España. ${ }^{5}$ De este modo, México sirvió de puente comercial entre Asia y Europa durante los años del período colonial. Entre dos y cuatro veces al año, los galeones españoles zarpaban de Veracruz con las mercancías orientales que previamente habían arribado, desde Manila, a las costas de Acapulco en la célebre Nao de China.

De Acapulco se enviaba plata (en barras o monedas), cochinilla para tintes, semillas, camote, tabaco, garbanzo, chocolate y cacao, sandía, vid e higueras de la Nueva España, y barricas de vino y aceite de oliva de España.

Desde Manila se embarcaban: de China, telas y objetos de seda (calcetas y pañuelos hasta colchas y manteles) y alfombras persas de Medio Oriente; piezas de algodón de la India; de China, del Sudeste de Asia (Conchinchina) y de Japón salían abanicos, cajoneras, arcones, cofres y joyeros laqueados, peines y cascabeles, biombos, escribanías y porcelanas. De las islas Molucas, Java y Ceilán, los marinos traían especias, principalmente clavo de olor, pimienta y canela. Otros productos de Oriente eran: lana de camello, cera, marfil labrado o tallado - con figuras religiosas-, bejucos para cestas, jade, ámbar, piedras preciosas, madera y corcho, nácar y conchas de madreperla, fierro, estaño, pólvora, frutas de China, entre otros.

Tanto en Asia como en América, los productos que arribaban a los puertos eran trasladados a los centros comerciales para ser vendidos. En Manila estaba el Parián de los Sangleyes, que era el centro del mercado asiático. En territorio americano estaba la feria de Acapulco y, desde principios del siglo XviII, el Parián de la Plaza Mayor de la Ciudad de México así como los mercados de Puebla y Jalapa, que eran los puntos de venta de productos asiáticos.
Una buena parte de los productos era trasladada a Veracruz para su embarque a España. Los que se distribuían tierra adentro iban hacia los centros mineros y las ciudades importantes del Bajío y Oaxaca. Como casi todos los productos asiáticos eran bienes de lujo, sólo las familias ricas de la Nueva España podían comprarlos.

La Nao de China no sólo transportaba bienes, sino que también favorecía el intercambio cultural. El uso de la seda en los rebozos, abanicos y biombos, la porcelana y Talavera poblana, los esmaltes en juegos de mesas y aun costumbres como las peleas de gallos son de origen oriental. En 1815, debido a la situación política de Nueva España y la metrópoli española, los viajes de la Nao fueron suspendidos (Rueda, 1998; Martínez, 1984; Cruz, 1962).

Un siglo y medio después el intercambio comercial entre China y México se restableció. No obstante, en los años sesenta el comercio entre China y México fue esporádico e insignificante; en ese tiempo China exportó a México algunos productos para uso industrial y artículos de consumo como bolsas, discos, manufacturas de madera, pelucas, juguetes, por valor de algunos miles de pesos de la época e importó de México algodón en rama por valor de 30.8 millones de pesos (MDP) en 1965, ópalos tallados por valor de 55,000 pesos en 1966 y algodón en rama por valor de 54 MDP en 1971 (tabla 7).

Con el reestablecimiento de relaciones diplomáticas entre México y la República Popular China en 1972, se realizaron algunos intentos por llevar a cabo intercambios más significativos, pero las economías de ambos países no habían desarrollado ninguna complementariedad productiva. De esta forma, los productos comercializados directamente eran muy pocos y su valor comercial muy bajo. 
Tabla 7

La balanza comercial de México con China, 1961-1972 (Miles de pesos)

\begin{tabular}{lrrr}
\hline & Exportaciones & Importaciones & Saldo \\
\hline 1961 & - & - & - \\
1962 & - & - & - \\
1963 & - & 115 & -115 \\
1964 & - & 20 & -20 \\
1965 & 30,825 & 745 & 30,080 \\
1966 & 55 & 297 & -242 \\
1967 & 2 & 124 & -122 \\
1968 & - & 3 & -3 \\
1969 & - & - & - \\
1970 & - & - & - \\
1971 & 54,038 & 203 & 53,835 \\
$1972 a$ & 21,572 & 552 & 21,020 \\
\hline
\end{tabular}

a. Enero-junio.

Fuente: Secretaría de Industria y Comercio, Dirección General de Estadística.

A partir de los años ochenta el intercambio comercial entre México y China ha tenido un crecimiento sin precedentes, sobre todo los flujos de China hacia México. El intercambio comercial ha crecido de manera simultánea a la participación de ambos países en la economía mundial. Anteriormente las economías de China y México eran poco competitivas, sus intercambios eran poco significativos, esporádicos y selectivos, circunscritos a un limitado número de productos. Sin embargo, al involucrarse en los procesos globales de producción-comercialización, ambas naciones ahora cumplen un papel específico dentro de la división internacional del trabajo, con tareas productivas específicas que definen el tipo y alcance de sus relaciones comerciales. De este modo, varias ramas productivas de la economía mexicana se ubican en las fases intermedias o finales de cadenas productivas que incluyen a la planta industrial de China y de otros países de Asia y América. Es por ello que el problema del desequilibrio comercial trascendió la relación entre los dos países.

En este contexto se da la dinámica de la integración regional y la participación de ambos países en organismos internacionales como la Organización Mundial de Comercio (Dussels, 2005) y APEC, por los cuales adquieren compromisos y derechos que configuran su participación en las economías regionales de Asia y América, así como las de alcance global. Específicamente, los flujos de comercio y capital - sobre todo los que se dan a través de la inversión extranjera directa-, inciden sobre la configuración de la estructura productiva interna, la balanza de pagos, la transferencia de tecnología, la competitividad, el empleo y el medio ambiente. ${ }^{6}$

Los productos finales de origen chino también han contribuido al desequilibrio en la relación comercial China-México. Las empresas ubicadas en ese país, tanto de capital local como de inversiones conjuntas y/o capital foráneo, luchan por ocupar un espacio mayor en el mercado mexicano. De esta manera en 2004 el déficit comercial de México con China casi alcanzó 14,000 MDD (tabla 8$){ }^{7}$

El hecho de que el tipo de relación productiva y comercial no sea privativa de China y México, sino de un sistema productivo, comercial y de flujo de capitales a escala global, se aprecia en la relación comercial de México con el resto de los países del Pacífico asiático. En la tabla 9 se percibe que la relación comercial más desventajosa para México es con las economías menos desarrolladas de la región de Asia. Al relacionar las importaciones con las exportaciones tenemos que con Malasia existe una relación de 78 a 1 , puesto que en 2004 México importó productos por valor 
$\underline{\text { Análisis }}$

Tabla 8

El comercio de México con China, 1990-2004

\begin{tabular}{rrrrr}
\hline & Exportaciones & Importaciones & \multicolumn{1}{c}{ Total } & \multicolumn{1}{c}{ Saldo } \\
\hline 1990 & 8,989 & 15,842 & 24,831 & $-6,853$ \\
1991 & 62,639 & 142,375 & 205,014 & $-79,736$ \\
1992 & 20,639 & 430,167 & 450,806 & $-409,528$ \\
1993 & 44,781 & 386,449 & 431,230 & $-341,668$ \\
1994 & 42,168 & 499,659 & 541,827 & $-457,491$ \\
1995 & 37,008 & 520,588 & 557,596 & $-483,580$ \\
1996 & 38,286 & 759,711 & 797,997 & $-721,425$ \\
1997 & 45,885 & $1^{\prime} 247,381$ & $1^{\prime} 293,266$ & $-1^{\prime} 201,496$ \\
1998 & 105,984 & $1^{\prime} 616,502$ & $1^{\prime} 722,486$ & $-1,510,518$ \\
1999 & 126,345 & $1^{\prime} 921,062$ & $2^{\prime} 047,407$ & $-1^{\prime} 794,717$ \\
2000 & 203,592 & $2^{\prime} 879,624$ & $3^{\prime} 083,216$ & $-2^{\prime} 676,032$ \\
2001 & 281,782 & $4^{\prime} 027,259$ & $4^{\prime} 309,041$ & $-3^{\prime} 745,477$ \\
2002 & 455,942 & $6^{\prime} 274,386$ & $6^{\prime} 730,328$ & $-5^{\prime} 818,444$ \\
2003 & 463,024 & $9^{\prime} 400,837$ & $9^{\prime} 863,861$ & $-8^{\prime} 937,813$ \\
2004 & 466,733 & $14^{\prime} 457,727$ & $14^{\prime} 924,460$ & $-13^{\prime} 990,994$ \\
\hline
\end{tabular}

Fuente: Secretaría de Economía.

de 3,407.0 MDD mientras que sus exportaciones apenas sumaron 43.5 MDD. En este mismo sentido la relación comercial con Filipinas es de 69 a 1, con Tailandia de 50 a 1, con China de 31 a 1 y con Vietnam de 32 a 1.

Con las economías más desarrolladas de la región del Pacífico asiático la relación es menos desigual. Con Japón es de 2.4 a 1, con Hong Kong de 1.5 a 1, con Taiwán de 2.4 a 1, con Corea del Sur de 7.3 a 1 y con Singapur de 8.4 a 1. Sin embargo, el mayor déficit comercial lo tiene México con China, porque en 2004 casi alcanzó 14,000 MDD, Malasia con 3,363.5 MDD, Japón con 3,010 MDD y Corea del Sur con 2,582.6 MDD.

Lo anterior pone de manifiesto que el problema del déficit de México con China, y por extensión con el área del Pacífico asiático, va más allá de las estrategias de comercialización de ambos países para ubicarse en la corriente global de bienes y servicios, que asignan un papel específico a las economías nacionales dentro del contexto mundial.

\section{El comercio de México y China con Estados Unidos}

El comercio de México y China con Estados Unidos, tanto en su volumen como en su estructura, es otro factor preocupante para México. En los últimos veinte años ambos países han incrementado de manera muy significativa su comercio con EU y han logrado una relación de intercambio superavitaria. Sin embargo, por una parte la velocidad de la participación de China en el mercado de Estados Unidos ha sido muy superior a la de México y, por la otra, los productos chinos están desplazando a los de origen mexicano que habían logrado penetrar el mercado estadounidense.

De 1985 a 2005 las importaciones y las exportaciones de México a Estados Unidos crecieron de manera casi paralela; las importaciones de México se incrementaron a una tasa anual promedio de $12.31 \%$, mientras que las exportaciones de México a Estados Unidos lo hicieron a una tasa de $11.92 \%$. 
El comercio exterior de China y su relación con México. Una perspectiva histórica

Tabla 9

Las relaciones comerciales de México con Asia Pacífico, 2004

\begin{tabular}{lrrrrrr}
\hline Año & Exportaciones & Importaciones & Intercambio & Saldo & Porcentaje & $\begin{array}{c}\text { Relación } \\
\text { imp./exp. }\end{array}$ \\
\cline { 2 - 4 } China & \multicolumn{5}{c}{ (millones de dólares) } \\
Japón & 467.0 & $14,458.0$ & $14,925.0$ & $-13,991.0$ & 49.1 & 30.9 \\
Corea del Sur & $2,172.0$ & $5,182.0$ & $7,354.0$ & $-3,010.0$ & 10.6 & 2.4 \\
Indonesia & 411.3 & $2,993.9$ & $3,405.2$ & $-2,582.6$ & 9.1 & 7.3 \\
Malasia & 14.4 & 616.7 & 631.1 & -602.4 & 2.1 & 42.9 \\
Filipinas & 43.5 & $3,407.0$ & $3,450.5$ & $-3,363.5$ & 11.8 & 78.3 \\
Singapur & 12.7 & 878.2 & 890.9 & -865.4 & 3.0 & 68.9 \\
Tailandia & 264.0 & $2,229.0$ & $2,493.0$ & $-1,965.0$ & 6.9 & 8.4 \\
Hong Kong & 25.3 & $1,272.6$ & $1,297.9$ & $-1,247.3$ & 4.4 & 50.4 \\
Taiwán & 279.6 & 422.2 & 701.8 & -142.6 & 0.5 & 1.5 \\
Vietnam & 414.0 & 978.0 & $1,392.0$ & -564.0 & 2.0 & 2.4 \\
Brunei & 7.7 & 177.9 & 185.7 & -170.2 & 0.6 & 23.0 \\
Suma & - & 0.2 & 0.2 & -0.2 & 0.0 & - \\
\hline
\end{tabular}

Fuente: Bancomext.

Por su parte, en el mismo periodo China reportó un aumento anual promedio de $13.74 \%$ en las importaciones de Estados Unidos y un aumento sin precedentes en sus exportaciones de $23.33 \%$ anual en el mismo periodo. Ello ha originado que, con un comercio equilibrado de 3,860 MDD de importaciones y exportaciones en 1985, China reporte en 2005 importaciones de Estados Unidos con valor de 41,836 MDD y exportaciones por $243,462 \mathrm{MDD}$, lo cual representa un déficit de 201,625.8 MDD para la economía de Estados Unidos.

En la relación comercial de China y México con Estados Unidos, como podemos apreciar en la gráfica 2, a partir de 2002 las exportaciones chinas a Estados Unidos superaron a las de México.

\section{Conclusión}

Con la llegada de los europeos a América y Asia las sociedades autóctonas de estos continentes, convertidas en colonias, fueron integradas a un sistema económico que por primera vez en la historia abarcó a todo el mundo. Los procesos de descolonización política que se dieron desde finales del siglo xx se han dado a la par de una mayor integración económica y de ajustes en la división internacional del trabajo, producto del avance tecnológico. Con el avance de la tecnología la integración se ha hecho más intensa.

Los procesos actuales de incorporación de México y China a la economía mundial se realizaron de manera casi simultánea -aunque con diversos matices, producto de su situación económica y política particular-. Iniciaron a principios de los años ochenta, recibieron un impulso definitivo en la década de 1990 y continúan en la actualidad con los ajustes necesarios que les imponen su compromisos adquiridos con el sistema económico internacional a través de los organismos internacionales.

En China el sistema de planificación del comercio exterior fue gradualmente desmantelado en los años ochenta. Las políticas de liberalización interna, apertura 
y participación en la economía mundial, aplicadas por la dirigencia china, se han manifestado sobre todo a través de la participación en comercio mundial y en la recepción de inversión extranjera directa. El creciente papel de las empresas extranjeras y del capital internacional en segmentos claves de la economía nacional se refleja en la integración a las cadenas productivas globales. En este contexto se ubica la relación comercial con México.

A partir de los años ochenta, con la incorporación más activa de ambos países a la economía mundial y con base en la lógica - y el interés- de las grandes empresas globales de incorporar las plataformas de producción de ambos países a una nueva división internacional del trabajo, se activó un comercio más regular entre México y China. De ahí que las relaciones comerciales se hayan caracterizado por la dinámica de la globalización, en la cual los flujos de inversión y capital obedecen principalmente a las necesidades externas. Como podemos apreciar, la participación significativa de China en el comercio mundial es un proceso que inició hace varios siglos y que por condiciones políticas internas y la situación internacional se vio interrumpido durante varios decenios. Los sucesos actuales son una continuación lógica del desarrollo económico global: China y el resto de Asia luchan por un espacio en el marco de un ambiente internacional

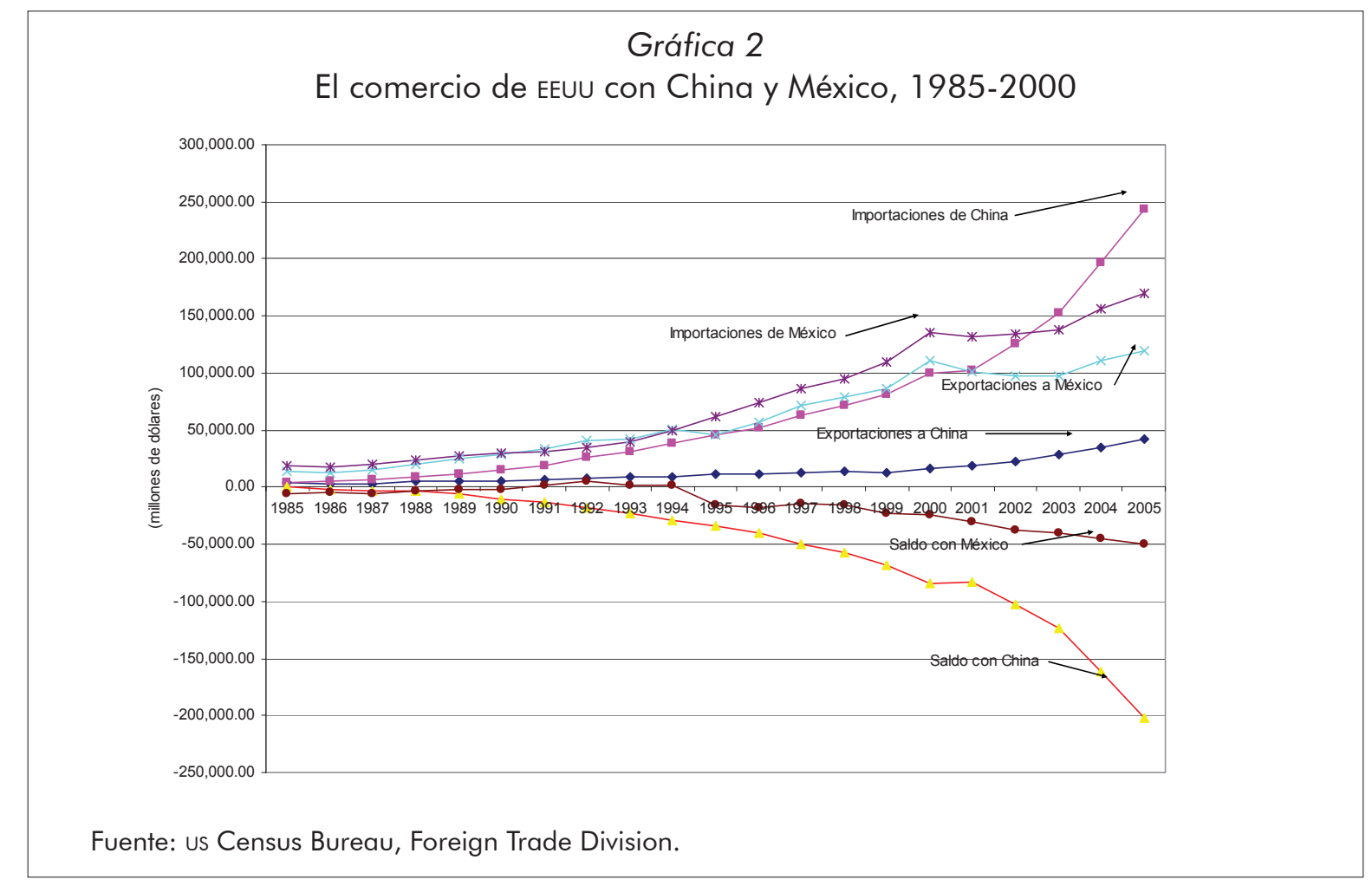


que se debate entre la preponderancia de un hegemón y la búsqueda de un esquema multilateral equilibrado con la participación activa y soberana de países de todos los continentes. my

\section{Notas}

1 El comercio tributario consistía fundamentalmente en que las naciones contiguas a China, que tenían un estatus jurídico de protectorado, visitaban al emperador periódicamente llevándole mercancías de su lugar de origen en forma de tributo. El emperador correspondía con regalos que en muchos casos sobrepasaba el valor de lo recibido Higging (1992: 30).

2 Japón desempeñó un papel importante en ambos lados de la matriz comercial seda-plata (Flynn, Frost y Latham, 1999).

3 Las exportaciones e importaciones de China crecieron a una tasa anual promedio de $15 \%$ de 1979 a 2003, mientras que la expansión comercial mundial fue de $7 \%$ en el mismo periodo (Prasad, 2004: 1).

4 En 1521 sucedieron dos acontecimientos que hicieron posible la anhelada ruta entre España y Asia: Sebastián Elcano, que lideraba la expedición de Magallanes, descubrió las Filipinas y Hernán Cortés conquistó Tenochtitlán. Cincuenta años después estas dos tierras remotas se conectaron por el comercio interoceánico y, de este modo, se cumplió el sueño comercial de España.

5 En 1565 Andrés de Urdaneta encontró las corrientes marítimas que permitían el retorno al continente americano. El tornaviaje salía de Manila, subía por las costas de Japón para encontrar la corriente de regreso y encontrar el litoral de California, de donde bajaban a su destino en la bahía de Acapulco. Como los barcos venían muy cargados de mercancías, podían tardar entre cuatro, cinco y hasta siete meses en llegar a las costas de América.

6 Para más detalles sobre la inversión extranjera directa y su correlación con otros aspectos relacionados con el desarrollo económico, véanse Gestrin (2002) y UNCTAD (2003).

7 Cabe señalar que existe una gran diferencia en las cifras de comercio exterior reportadas por China y México, producto de la metodología para recopilar la información estadística de cada país. Solamente en 2004 México reporta un déficit de 13,991 MDD, mientras que China lo hace por 2,845.7 MDD, como se puede apreciar en el siguiente cuadro. Para más detalles sobre estas diferencias, véase Dussel (2005).

Comercio de China con México, 2001-2005 (En miles de millones de dólares)

\begin{tabular}{|c|c|c|c|c|c|}
\hline & 2001 & 2002 & 2003 & 2004 & $2005^{a}$ \\
\hline Exportaciones & $1,795.9$ & $2,864.4$ & $3,267.8$ & $4,977.5$ & $2,459.4$ \\
\hline Importaciones & 761.1 & $1,115.2$ & $1,677.0$ & $2,131.8$ & $1,033.6$ \\
\hline Saldo & $1,034.8$ & $1,749.2$ & $1,590.8$ & $2,845.7$ & $1,425.8$ \\
\hline
\end{tabular}

\section{Referencias bibliográficas}

Cruz, F. (1962), La Nao de China, Jus Editorial, México, DF.

Dussels, E. (2005), "El caso de las estadísticas comerciales entre China y México: para empezar a sobrellevar el desconocimiento bilateral", en Economía Informa, UNAM, núm. 335, pp. 50-61.

- (2005a), "The Implications of China's Entry into the WTo for Mexico, Global Issue Papers núm. 24, Heinrich Böll Foundation, Berlín.

Feuerweker, A. (s/a), The Chinese Economy, University of Michigan Press, Ann Arbor.

Flynn, D., L. Frost y A. Latham (1999), Pacific Centuries: Pacific and Pacific Rim History since the 16th Century, Routledge, Londres y Nueva York.

Gestrin, M. (2002), The Relationship between Trade and Foreign Direct Investment: A Survey, Trade Committee, OCDE, París.

Higging, R. (1992), "The Tributary System", en M. Borthwick, Pacific Century. The Emergence of Modern Pacific Asia, Westview Press, Boulder, Colorado.

IMF (2005), International Financial Statistics, Washington, DC.

Maddison, A. (1999), Chinese Economic Performance in the Long Run, OECD Development Centre, París.

Martínez, J. (1984), Pasajeros de indias, Alianza Editorial Mexicana, México, DF.

Prasad, E. (2004), "China's Growth and Integration into the World Economy. Prospects and Challenges", Occasional Paper núm. 232, International Monetary Fund, Washington, DC.

Rueda, S. (1998), "La Nao de China, riqueza a contracorriente", en Arqueología Mexicana, México, vol. 6, núm. 33.

Rumbaugh, T. y N. Blancher (2004), "China: International Trade and WTO Accession", Working Paper núm. 04/36, Fondo Monetario Internacional, Washington, DC.

UNCTAD (2003), World Investment Report 2003. FDI Policies for Development: National and International Perspectives, Naciones Unidas, Nueva York. 